\title{
Precipitating Factors of Psoriasis in North Indian Population
}

\author{
Kumar Bhaskar K. ${ }^{1}$, Chawla K. ${ }^{2}$, B. $^{3}$, Mishra A. ${ }^{4}$, Kumar Shukla R. ${ }^{*}$ \\ DOI: https://doi.org/10.17511/ijmrr.2021.i05.01
}

\footnotetext{
${ }^{1}$ Kamlesh Kumar Bhaskar, Consultant, Department of Skin \& V.D., District Hospital, Gazipur, Uttar Pradesh, India.

2 Kavita Chawla, Professor, Department of Physiology, Moti Lal Nehru Medical College, Prayagraj, Uttar Pradesh, India.

3 Beenu, Professor, Department of Biochemistry, Moti Lal Nehru Medical College, Prayagraj, Uttar Pradesh, India.

${ }^{4}$ Archana Mishra, Assistant Professor, Department of Biochemistry, Moti Lal Nehru Medical College, Prayagraj, Uttar Pradesh, India.

5* Rakesh Kumar Shukla, Assistant Professor, Department of Anatomy, Autonomous State Medical College, Mirzapur, Uttar Pradesh, India.
}

\begin{abstract}
Aim: This study aims to study precipitating factors of psoriasis in the north Indian population. Material \& Method: Two hundred twenty-eight psoriasis patients regardless of age, sex, religion, occupation, attending the skin, and V.D. outpatients Department, B.R.D. Medical College, Gorakhpur for were taken because of the subject of this study. The bulk of patients belonged to the Eastern U.P. and adjoining areas of Bihar and Nepal. The clinical criteria for diagnosis of psoriasis were the presence of Erythematous and papulosquamous lesions with loosely adherent silvery-white scales. The auspitz's sign was demonstrated all told the cases. The detailed clinical history and examination were recorded. Each patient was categorized into mild to severe psoriasis. Result: The maximum percentage of cases was aggravated by weather (winter), 55.26\%, next to that was trauma 27.1 $9 \%$, and least after infections $4.35 \%$. The summer and spring seasons showed an improved effect on the condition of psoriasis. Alcohol, smoking, and mental stress found no relation with psoriasis. In most cases, where the infection was associated with the disease, it had been aggravated only in children, and young adults and lesions were of guttate type. Pregnancy had no effect in $25.43 \%$ of cases, while the disease was improved in $3.50 \%$ of patients and worsen in $4.35 \%$ of cases. Conclusion: Psoriasis is positively correlated with the winter season and negatively associated with Summer and Spring.
\end{abstract}

Keywords: Psoriasis, Precipitating factors, Psoriasis plaque, Psoriasis-Arthritis

\section{Corresponding Author}

Rakesh Kumar Shukla, Assistant Professor, Department of Anatomy, Autonomous State Medical College, Mirzapur, Uttar Pradesh, India. Email: 0522rakesh@gmail.com

\section{How to Cite this Article}

Kamlesh Kumar Bhaskar, Kavita Chawla, Beenu, Archana Mishra, Rakesh Kumar Shukla, Precipitating Factors of Psoriasis in North Indian Population. Int J Med Res Rev. 2021;9(5):280-285.

Available From

https://ijmrr.medresearch.in/index.php/ijmrr/article/ view/1323
To Browse

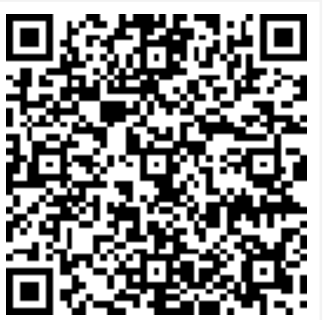

Manuscript Received 2021-08-03

Conflict of Interest No
Review Round 1 2021-08-13

Funding

Nil

Review Round 2
2021-08-21
Ethical Approval
Yes

Review Round 2

Yes
Review Round 3 2021-08-29

Plagiarism X-checker $5 \%$
Accepted 2021-09-03

Note

(C) 2021 by Kamlesh Kumar Bhaskar, Kavita Chawla, Beenu, Archana Mishra, Rakesh Kumar Shukla and Published by Siddharth Health Research and Social Welfare Society. This is an Open Access article licensed under a Creative Commons Attribution 4.0 International License https://creativecommons.org/licenses/by/4.0/ unported [CC BY 4.0]. 


\section{Introduction}

Psoriasis is a common, genetically determined chronic, relapsing, inflammatory disorder of the skin characterized by red, scaly, sharply demarcated plaques that typically exhibit silvery-white scales. Psoriasis is one of the significant common chronic inflammatory diseases of the skin, affecting 2-3\% of the population [1]. Up to now, there's no cure known for this disease, which is related to the extensive psychological and physical burden. This disease evolves overtime in an exceedingly complex interplay of heterogeneous genetic and environmental factors [2]. Psoriasis isn't only a skin problem but may additionally include inflammation of the joints in psoriasis arthritis [3] and comorbidities like metabolic syndrome with increased insulin resistance, increased cardiovascular risk $[4,5]$. Several risk factors and pathways are known to enable the event of psoriasis. Genetic factors seem to possess a task when interacting with environmental factors like drugs, stress, or streptococcal infection [6]. Almost all styles of trauma are known to be related to plaque psoriasis.

Additionally, excessive scratching can trigger or aggravate localized psoriasis. The event of psoriatic plaques at any site of trauma is thought of because of the koebner reaction. The emergence of the latest psoriatic lesions within the non-involved (healthy) skin region following an injury/trauma to the healthy skin areas of psoriatic patients [7]. Sunlight is understood to be beneficial for patients with plaque psoriasis; however, during a small number of patients, the disorder could also be aggravated by light. Clinical improvement of psoriasis following sun exposure is preceded by a rapid reduction in local and systemic inflammatory markers, strongly suggesting that immune modulation mediated the observed clinical effect [8]. It was recently reported that tonsils from patients with psoriasis are more frequently infected with $\beta$-haemolytic streptococci, especially group $C$ streptococci, than recurrently infected tonsils from patients without psoriasis [9]. Nevertheless, the immunological basis for the association of psoriasis and streptococcal throat infections continues to be under investigation.

\section{Material and Methods}

This study was conducted at the O.P.D. of the Department of the skin and V. D. B.R.D. Medical
College, Gorakhpur. The total duration of the study was 16 months, and this study was a Cohort study (prospective and observational). A systematic sampling method was followed for sample collections; the bulk of patients belonged to the Eastern U.P. and adjoining areas of Bihar and Nepal. The sample size was calculated using the online software available at www. clinical.com; a total of two hundred twenty-eight psoriasis cases were identified for study. Inclusion criteria for study followed: Psoriasis regardless of age, sex, religion, occupation, medical conditions. Exclusion criteria for the study: Psoriasis cases from Geographically other than North India, Unable to follow up, and any other dermatological disorder associated. The clinical criteria for diagnosis of psoriasis were the presence of Erythematous and papulosquamous lesions with loosely adherent silvery-white scales.

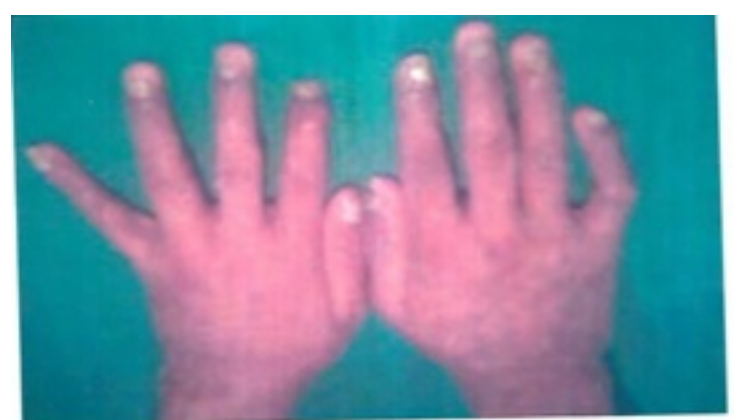

Psoriatic arthritis with asymmetrical distal interphalangeal joint involvement

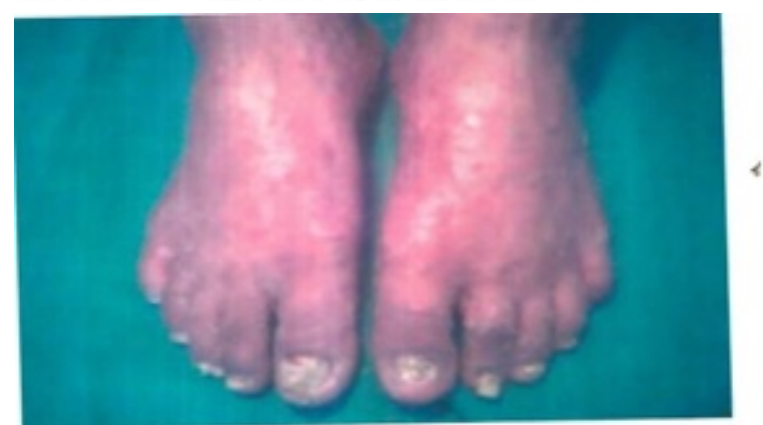

Psoriatic arthritis of left grate toe with nail involvement

The auspitz's sign was demonstrated all told the cases [10]. The patients in whom joint involvement the diagnosis was made based totally on history, physical examination, the same old absence of R.F. (Rheumatoid factor), and radiological features. The physical examination excludes assessment of number, location, as distribution of joints involved, together with the presence of psoriatic skin lesion, key signs and symptoms indicative of rheumatism include asymmetrical joint involvement, Enthesitis, 
Dactylitis, distal inter phalange (D.I.P.), and proximal inter phalange (P.I.P.) involvement and spinal inflammation.

The detailed clinical history and examination were recorded. Each patient was categorized into mild to severe psoriasis.

Each patient has undergone the following investigation.

01 . Routine blood tests

02. Liver function test, kidney function test (if required)

\section{Skin biopsy}

04. Tests for Rheumatoid factor and serum uric acid.

05. Radiographs of both hands and feet.

06. Radiographs of the lumbosacral spine and both sacroiliac joints.

07. Radiographs of affected joints (if any).

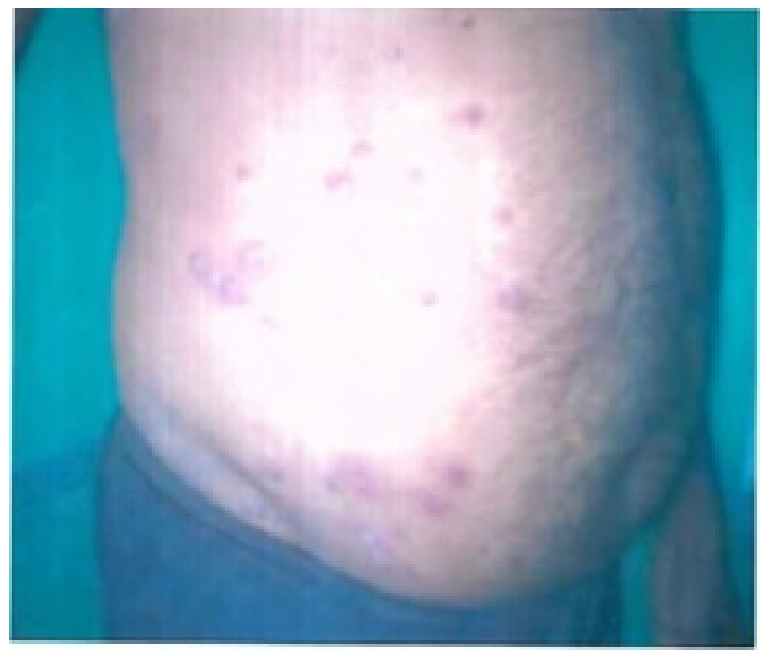

\section{Psoriasis (plaque type)}

\section{Observation}

This study was conducted on 228 patients with psoriasis attending the Dermatology outpatient department of Nehru Hospital, B.R.D. Medical College, Gorakhpur, from July 2005 to October 2006.

Table 1: Age and Sex Distribution of the subjects

\begin{tabular}{|l|l|l|l|l|l|l|}
\hline \multirow{2}{*}{ Age (Years) } & \multicolumn{2}{c|}{ Male } & \multicolumn{2}{c|}{ Female } & \multicolumn{2}{c|}{ Total } \\
\cline { 2 - 7 } & No & $\%$ & No & $\%$ & No & $\%$ \\
\hline $0-10$ & 06 & 02.63 & 06 & 02.63 & 12 & 05.26 \\
$11-20$ & 18 & 07.89 & 28 & 12.28 & 46 & 20.16 \\
\hline
\end{tabular}

\begin{tabular}{|l|l|l|l|l|l|l|}
\hline $21-30$ & 36 & 15.78 & 24 & 10.52 & 60 & 26.31 \\
$31-40$ & 34 & 14.51 & 18 & 07.89 & 52 & 22.80 \\
$41-50$ & 20 & 08.77 & 12 & 05.26 & 32 & 14.03 \\
$51-60$ & 16 & 07.01 & 02 & 00.87 & 18 & 07.89 \\
$61-70$ & 06 & 04.35 & & & 06 & 04.35 \\
$71-80$ & 02 & 00.87 & & & 02 & 00.87 \\
\hline Total & 138 & 100.0 & 90 & 100.0 & 228 & 100.0 \\
\hline
\end{tabular}

The total numbers of cases studied were 228, of which males were 138 and females were 90. the maximum numbers of patients were within the cohort of two 1-30 years. In males, most cases were within 21-30 years, while in females, 11 -20years.

\section{Table 2: Precipitating Factors}

\begin{tabular}{|l|l|l|l|l|l|l|}
\hline \multirow{2}{*}{ Factors } & \multicolumn{2}{|c|}{ Aggravated } & \multicolumn{2}{|c|}{ Improved } & \multicolumn{2}{|c|}{ No Effect } \\
\cline { 2 - 7 } & No & $\%$ & No & $\%$ & No & $\%$ \\
\hline Throat infection & 10 & 04.35 & - & - & 218 & 95.61 \\
Mental stress & 16 & 07.01 & - & - & 212 & 92.98 \\
Trauma & 62 & 27.19 & - & - & 166 & 72.80 \\
Alcohol/Smoking & 10 & 04.35 & - & - & 218 & 95.61 \\
Pregnancy & 10 & 04.35 & 08 & 03.50 & 58 & 25.43 \\
Sunlight & 30 & 14.03 & 48 & 21.50 & 148 & 64.90 \\
Dialysis & - & - & - & - & - & - \\
Weather & & & & & & \\
- Summer & 44 & 19.29 & 110 & 43.86 & 74 & 32.45 \\
- Winter & 126 & 55.26 & 36 & 15.78 & 66 & 28.94 \\
- Spring & 50 & 21.92 & 98 & 42.98 & 80 & 35.08 \\
\hline
\end{tabular}

The maximum percentage of cases was aggravated by weather (winter), 55.26\%, next to that was trauma $27.19 \%$, and least after infections $4.35 \%$. The summer and spring seasons showed an improved effect on the condition of psoriasis. Alcohol, smoking, and mental stress found no relation with psoriasis. In most cases, where the infection was associated with the disease, it had been aggravated only in children, and young adults and lesions were of guttate type. Pregnancy had no effect in $25.43 \%$ of cases, while the disease was improved in $3.50 \%$ of patients and worsen in $4.35 \%$ of cases.

\section{Discussion}

Our study indicated that $55.26 \%$ of patients with psoriasis had aggravation of disease conditions in fall/winter. The seasonality peaking of psoriasis has been observed in clinical practice, verified by the numerous seasonal variation in dermatologic office visits [11]. Observational investigations, supported Google Trends datasets, showed that the general public interest in seeking psoriasis-related information displayed a seasonal trend. 
The very best interest appeared in late winter and early spring [12]. The trend of online researches also implied the association between the psoriasis flare and, therefore, the weather. Our study shows that in summer, psoriasis condition improves in 43.8 $6 \%$ where is aggravated in $19.29 \%$ and remain affected in $32.45 \%$. Psoriasis in winter aggravated in $55.26 \%$, improved in $15.78 \%$ and had no effect in $28.94 \%$. In spring, it gets aggravated in 21.9 to twenty-eight improve in $42.98 \%$ and no effect in $35 \%$. In presence of sunlight improved in $21.50 \%$ aggravated in $14.03 \%$ and remain unaffected in $64.90 \%$. Heinrich Koebner (1838-1904) reported the emergence of the latest psoriatic lesions within the non-involved (healthy) skin region following an injury/trauma to the healthy skin areas of psoriatic patients [7].

Still, within the present study, most of the patients were household workers and farmers. Thanks to the character of their profession, minor trauma might well be ignored, which could are related to the disease. Patients with psoriasis were 4-5 times more likely to be colonized by Staphylococcus aureus (S. aureus) on the skin and $60 \%$ more likely to be colonized within the cavity compared with healthy controls [relative risk and $95 \%$ confidence interval (CI), skin: 5.54 (3.21-9.57); nares: 1.60 (1.112.32)] [13]. In our study, 4.35 percent of patients with psoriasis reported pharyngitis, and during this, children and young adults below 20 years were more affected. Smoking [14-18]. And metabolic syndrome $[18,19]$ are recognized as risk factors for severe psoriasis, but our study shows alcohol smoking, and mental stress found no relation with psoriasis.

Pregnancy in women with psoriasis represents a high-risk situation thanks to the limited therapeutic options and multiple comorbidities [20,21]. Moderate-to-severe psoriasis is associated during pregnancy with pregnancy-induced hypertensive disorders, low birth weight (L.B.W.) for age, preterm birth (PTB), depressive disorders, and gestational diabetes [21]. Even abortion [22-24] during this study, we found that 4.35 percent of pregnant women with psoriatic cases found it aggravated; in $3.5 \%$ cases, the condition improved, whereas 25.4 $3 \%$ cases remain unaffected with pregnancy.

\section{Conclusion}

Psoriasis is aggravated during winter, but in summer and spring condition improves. At the same time, alcohol and smoking found no effect on psoriasis.
Psoriasis correlation with sunlight, pregnancy and trauma need more study. The impact of psoriasis on the physical, mental, social and financial aspects of life should not be underplayed and considered as necessary as other chronic conditions. Advancement in the cellular immunology and biology of psoriasis will improve this research.

\section{The outcome of this study}

In the North Indian population, psoriasis condition improves in summer to $43.86 \%$ and aggravated to $55.26 \%$ in winter.

Disclosure: The authors declare that there is no conflict of interest.

\section{Author Contribution}

K.B.: Data collection, Methodology, R.S.: a review of literature, K.C.: statistical analysis, data interpretation, B.: statistical analysis, data interpretation, AM: final approval, Review of the literature.

\section{What does this study add to existing knowledge?}

The impact of psoriasis on the physical, mental, social and financial aspects of life should not be underplayed and must be considered with the same importance as other chronic conditions.

\section{Reference}

01. Wagner EF, Schonthaler HB, Guinea-Viniegra J, Tschachler E. Psoriasis: what we have learned from mouse models. Nat Rev Rheumatol. 2010 Dec;6(12):704-14. doi: 10.1038/nrrheum.2010.157 [Crossref][PubMed][Google Scholar]

02. Di Cesare A, Di Meglio P, Nestle FO. The IL23/Th17 axis in the immunopathogenesis of psoriasis. J Invest Dermatol. 2009 Jun;129(6):1339-50. doi: 10.1038/jid.2009.59 [Crossref][PubMed][Google Scholar]

03. Winchester R, Minevich G, Kane D, et al. Heterogeneity of the psoriasis phenotype revealed by HLA class I haplotype associations in psoriatic arthritis and psoriasis. Clin Immunol. 2008; 127:S88-9. [Crossref][PubMed][Google Scholar] 
04. Vena GA, Altomare G, Ayala F, Berardesca E, Calzavara-Pinton $\mathrm{P}$, Chimenti $\mathrm{S}$, et al. Incidence of psoriasis and association with comorbidities in Italy: a 5-year observational study from a national primary care database. Eur J Dermatol. 2010 SepOct;20(5):593-8. doi: 10.1684/ejd.2010.1017 [Crossref][PubMed][Google Scholar]

05. Mehta NN, Yu Y, Pinnelas R, Krishnamoorthy $P$, Shin DB, Troxel AB, Gelfand JM. Attributable risk estimate of severe psoriasis on major cardiovascular events. Am J Med. 2011 Aug;124(8):775. e1-6. doi: 10.1016/j.amjmed.2011.03.028 [Crossref][PubMed] [Google Scholar]

06. Griffiths CE, Barker JN. Pathogenesis and clinical features of psoriasis. Lancet. 2007 Jul $21 ; 370(9583): 263-271$ doi: 10.1016/S01406736(07)61128-3 [Crossref][PubMed][Google Scholar]

07. Diani M, Cozzi C, Altomare G. Heinrich Koebner and His Phenomenon. JAMA Dermatol. 2016 Aug $1 ; 152(8): 919$. doi: 10.1001/jamadermatol.2015.6015 [Crossref] [PubMed][Google Scholar]

08. Søyland E, Heier I, Rodríguez-Gallego C, Mollnes $T E$, Johansen FE, Holven KB, et al. Sun exposure induces rapid immunological changes in skin and peripheral blood in patients with psoriasis. $\mathrm{Br}$ J Dermatol. 2011 Feb;164(2):344-55. doi: 10.1111/j.1365-2133.2010.10149.x [Crossref] [PubMed][Google Scholar]

09. Sigurdardottir $\mathrm{SL}$, Thorleifsdottir $\mathrm{RH}$, Valdimarsson $H$, Johnston $A$. The association of sore throat and psoriasis might be explained by histologically distinctive tonsils and increased expression of skin-homing molecules by tonsil $\mathrm{T}$ cells. Clin Exp Immunol. 2013 Oct;174(1):139-51. doi: 10.1111/cei.12153 [Crossref][PubMed][Google Scholar]

10. Bernhard, Jeffrey D. "Auspitz sign is not sensitive or specific for psoriasis". Journal of the American Academy of Dermatology. 22;6(1990):1079-1081. [Crossref][PubMed][Google Scholar]

11. Hancox JG, Sheridan SC, Feldman SR, Fleischer $A B$ Jr. Seasonal variation of dermatologic disease in the USA: a study of office visits from 1990 to 1998. Int J Dermatol. 2004 Jan;43(1):6-11. doi: 10.1111/j.1365-4632.2004.01828.x [Crossref] [PubMed][Google Scholar]
12. Wu Q, Xu Z, Dan YL, Zhao CN, Mao YM, Liu LN, Pan HF. Seasonality and global public interest in psoriasis: an infodemiology study. Postgrad Med J. 2020 Mar;96(1133):139-143. doi: 10.1136/postgradmedj-2019-136766 [Crossref] [PubMed][Google Scholar]

13. Ng CY, Huang YH, Chu CF, Wu TC, Liu SH. Risks for Staphylococcus aureus colonization in patients with psoriasis: a systematic review and metaanalysis. Br J Dermatol. 2017 Oct;177(4):967-977. doi: 10.1111/bjd.15366 [Crossref][PubMed][Google Scholar]

14. Wei, Shengcai, et al. "Study of the association between HLA-DQA1 alleles and environmental factors in psoriasis". Zhonghua liu xing bing xue za zhi= Zhonghua liuxingbingxue zazhi. 23;6(2002) :445-448. [Crossref][PubMed][Google Scholar]

15. Naldi L. Psoriasis and smoking: links and risks. Psoriasis (Auckl). 2016 May 27;6:65-71. doi: 10.2147/PTT.S85189 [Crossref][PubMed][Google Scholar]

16. Richer $\mathrm{V}$, Roubille $\mathrm{C}$, Fleming $\mathrm{P}$, Starnino $\mathrm{T}$, McCourt C, McFarlane A, et al. A Systematic Literature Review and Meta-Analysis With Qualitative Analysis of Effect of Smoking on Psoriasis Severity. J Cutan Med Surg. 2016 May;20(3):221-7. doi: 10.1177/1203475415616073 [Crossref][PubMed][Google Scholar]

17. Zeng J, Luo S, Huang Y, Lu Q. Critical role of environmental factors in the pathogenesis of psoriasis. J Dermatol. 2017 Aug;44(8):863-872. doi: 10.1111/1346-8138.13806 [Crossref][PubMed] [Google Scholar]

18. Adışen $E$, Uzun $S$, Erduran F, Gürer MA. Prevalence of smoking, alcohol consumption and metabolic syndrome in patients with psoriasis. An Bras Dermatol. 2018 Mar;93(2):205-211. doi: 10.1590/abd1806-4841.20186168 [Crossref] [PubMed][Google Scholar]

19. Singh S, Young $P$, Armstrong AW. Relationship between psoriasis and metabolic syndrome: a systematic review. G Ital Dermatol Venereol. 2016 Dec;151(6):663-677. [Crossref][PubMed][Google Scholar]

20. Yang YW, Chen CS, Chen YH, Lin HC. Psoriasis and pregnancy outcomes: a nationwide populationbased study. J Am Acad Dermatol. 2011 Jan;64(1):71-7. doi: 10.1016/j.jaad.2010.02.005 [Crossref][PubMed][Google Scholar] 
21. Bröms G, Haerskjold A, Granath F, Kieler $H$, Pedersen L, Berglind IA. Effect of Maternal Psoriasis on Pregnancy and Birth Outcomes: A Populationbased Cohort Study from Denmark and Sweden. Acta Derm Venereol. 2018 Aug 29;98(8):728-734. doi: 10.2340/00015555-2923 [Crossref][PubMed] [Google Scholar]

22. Horn EJ, Chambers CD, Menter A, Kimball AB. International Psoriasis Council, Pregnancy outcomes in psoriasis: why do we know so little?. J Am Acad Dermatol. 2009 Aug;61(2):e5-8. doi: 10.1016/j.jaad.2009.05.004 [Crossref][PubMed] [Google Scholar]
23. Ding $X$, Wang $T$, Shen $Y$, Wang $X$, Zhou C, Tian $S$, et al. Prevalence of psoriasis in China: a population-based study in six cities. Eur J Dermatol. 2012 Sep-Oct;22(5):663-7. doi: 10.1684/ejd.2012.1802 [Crossref][PubMed][Google Scholar]

24. Marino J, Paster J, Benichou G. Allorecognition by $\mathrm{T}$ Lymphocytes and Allograft Rejection. Front Immunol. 2016 Dec 14;7:582. doi: 10.3389/fimmu.2016.00582 [Crossref][PubMed] [Google Scholar] 